\title{
His bundle electrogram during bidirectional tachycardia
}

\author{
S. Gavrilescu and C. Luca \\ From the Department of Medicine and Cardiology, Institute of Medicine, Timisoara, Rumania
}

The case is reported of a 66-year-old woman with bidirectional tachycardia caused by digitalis intoxication. His bundle records demonstrated the presence of two foci, one junctional and the other a fascicular one.

Bidirectional tachycardia is a rare and dangerous arrhythmia associated with severe myocardial disease and digitalis toxicity (Schwensen, I922; Scherf and Cohen, 1964; Kastor, 1973). The explanation of its mechanism is controversial; the most favoured hypotheses include a supraventricular origin with aberrant conduction, and ectopic impulse formation within the ventricles. Right bundlebranch block is often, though not always, present, and conduction has been assumed to occur alternately through the anterior and posterior divisions of the left bundle (Rosenbaum, Elizari, and Lazzari, 1969). His bundle records have been obtained in a few cases (Cohen, Deisseroth, and Hecht, I973; Kastor and Goldreyer, 1973; Morris and Zipes, 1973; Puech et al., 1974) demonstrating the ventricular origin of the abnormal rhythm. A case is reported in which the recording of His bundle activity provided evidence in favour of a junctional focus, associated with a fascicular one.

\section{Case report}

The patient, a 66-year-old woman, was admitted to the hospital with signs of gross congestive heart failure. She was known to have had arterial hypertension from the age of 50, and had been admitted to hospital repeatedly during the previous four years because of congestive failure. During this period she was treated intermittently with digitalis and diuretic drugs. Four months before the last admission a left cervical adenopathy was noted. Persistent dizziness, shortness of breath, and occasional vomiting had occurred during the previous two weeks.

On admission, there was bilateral pitting ankle oedema, and there were bilateral basal crepitations; the liver extended four finger breadths below the right costal margin. The pulse rate was $1 \mathrm{ro} /$ minute and blood pressure $200 / \mathrm{r}$ Io $\mathrm{mm} \mathrm{Hg}(26.6 / 14.6 \mathrm{kPa})$. The cardiac impulse was felt in the fifth intercostal space in the anterior axillary line. On auscultation, there was a pansystolic murmur, maximal at the left sternal edge, which radiated to the left axilla. The admission electrocardiogram showed sinus rhythm and left ventricular hypertrophy. Laboratory data revealed a normal blood count, blood urea 12.5 $\mathrm{mmol} / 1(75 \mathrm{mg} / \mathrm{IO0} \mathrm{ml})$, blood glucose $4.99 \mathrm{mmol} / 1$ (90 $\mathrm{mg} / 100 \mathrm{ml}$ ), creatinine $132.6 \mu \mathrm{mol} / 1(1.5 \mathrm{mg} / 100 \mathrm{ml}$ ), sodium $135 \mathrm{mmol} / 1$, potassium $4.3 \mathrm{mmol} / 1$, chloride 98 $\mathrm{mmol} / \mathrm{l}$, and total bicarbonate $26 \mathrm{mmol} / \mathrm{l}$. The urine contained a trace of protein and microscopical haematuria. Chest $x$-ray showed moderate cardiomegaly, pulmonary venous congestion, and a small right pleural effusion.

The patient was confused and uncooperative. Lanatoside C ( $0.8 \mathrm{mg}$ ) and frusemide (40 $\mathrm{mg}$ ) were administered intravenously and $\mathrm{KCl}(6 \mathrm{~g})$ was given by mouth, daily. On the third day the patient developed atrioventricular dissociation and then atrial fibrillation with junctional tachycardia (not shown). Digitalis was stopped and the patient was monitored in the intensive care ward. Her clinical status deteriorated rapidly and bidirectional tachycardia occurred during this period (Fig. IA). The abnormal rhythm was abolished by $80 \mathrm{mg}$ lignocaine, intravenously. During bidirectional tachycardia the His bundle electrogram was recorded using a simple bedside method (Pop et al., 1972). In the following hours cardiac arrest occurred and the patient died on the fourth hospital day.

Necropsy revealed left ventricular hypertrophy and dilatation. The left ventricular wall was $3.5 \mathrm{~cm}$ thick. The pericardial sac contained a small quantity of bloodstained fluid $(100 \mathrm{ml})$. The coronary arteries and cardiac valves showed no gross abnormalities. Other significant necropsy findings included: pulmonary oedema, nephrosclerosis due to chronic glomerulonephritis, and tuberculous cervical adenitis.

\section{Electrocardiogram and His bundle electro- gram}

The electrocardiogram during bidirectional tachycardia (Fig. IA) revealed a slightly irregular ventricular rate of 120 beats a minute. There were sequences of beats with an electric axis that alternated in the frontal 
plane between $+40^{\circ}$ and $+110^{\circ}$. The $Q R S$ duration in praecordial leads was $0.12 \mathrm{~s}$ for the first type of ventricular complexes and $0.06 \mathrm{~s}$ for the second ones. The axis shifts were associated with a striking variation of the configuration of QRS complexes in lead VI and V6, suggesting a different origin of the beats. A wide $S$ wave was present in both types of beats. Atrial fibrillation was apparent in the right praecordial leads. Occasionally pauses occurred, which had the duration of two cycle lengths.

The His bundle electrogram recorded during the abnormal rhythm (Fig. IB) showed that both types of complex were associated with an $\mathbf{H}$ deflection. The cycle length of ventricular activity measured $500 \mathrm{~ms}$, with slight variations. The ventricular complexes of $+40^{\circ}$ axis were preceded by an $\mathrm{HV}$ interval of $50 \mathrm{~ms}$, while those showing a rightward axis presented an $\mathrm{H}^{\prime}$ deflection which coincided with the beginning of ventricular activation on surface electrocardiogram and an $\mathrm{H}^{\prime} \mathrm{V}^{\prime}$ interval of $10 \mathrm{~ms}$ on the His bundle electrogram. The ectopic beats showing an $\mathbf{H}^{\prime}$ deflection preceding narrow QRS complexes with an $\mathrm{H}^{\prime} \mathrm{V}^{\prime}$ interval of $\mathrm{IO} \mathrm{ms}$ are believed to be fascicular beats arising high in the left branch of the His bundle. The beats showing an $\mathrm{H}$ deflection, with QRS complexes, and HV interval $50 \mathrm{~ms}$ are believed to be junctional in origin. Fusion beats with an

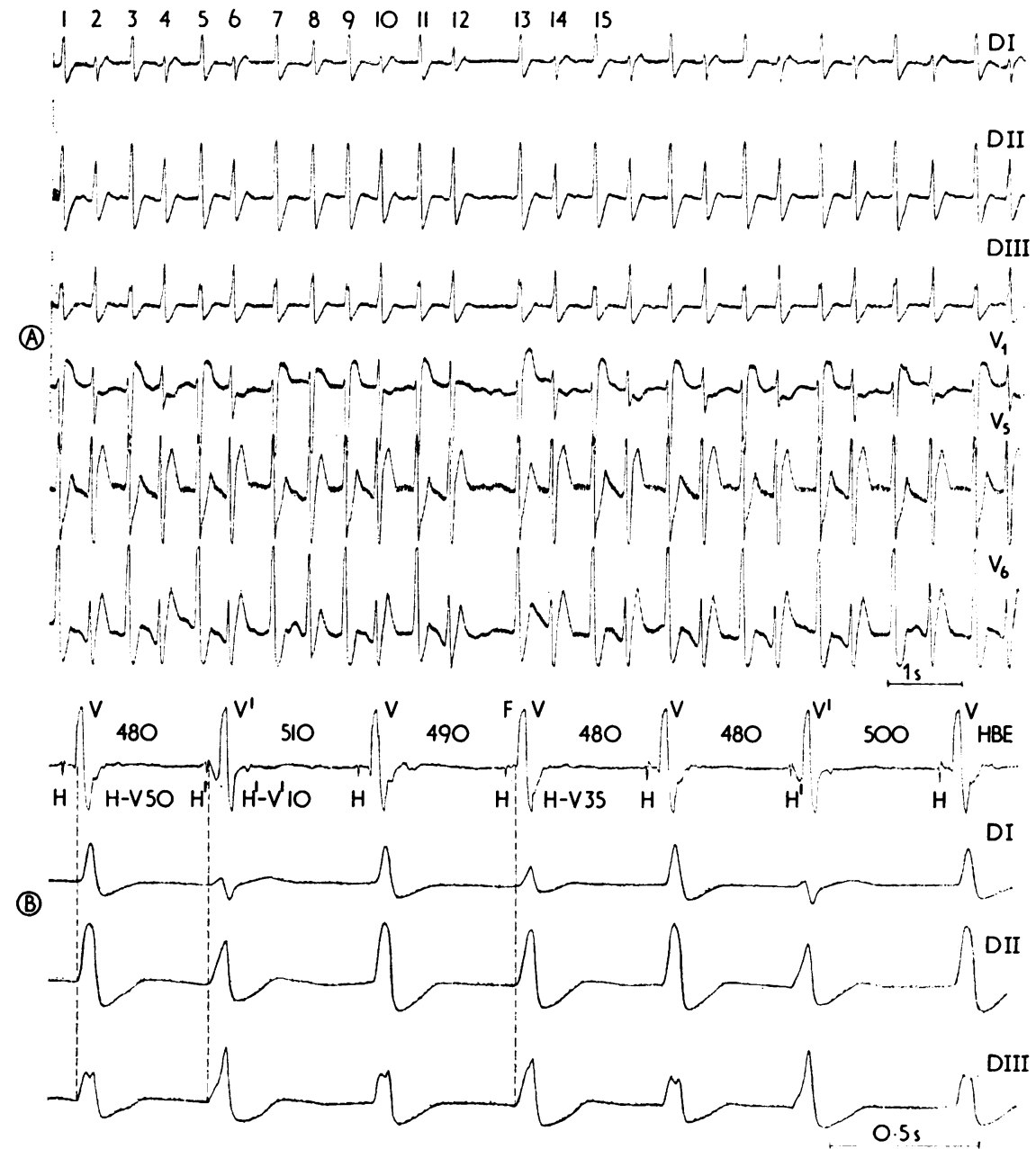

FIG. I A) Upper panel. Surface electrocardiogram during bidirectional tachycardia. Atrial fibrillation can be recognized in lead VI. The pause in the middle of the tracing is equal to two cycle lengths. B) Lower panel. His bundle electrogram (HBE) recorded simultaneously with leads I, II, and III. Cycle lengths are given for each recorded complex. V: ventricular activation caused by junctional beats, $V^{\prime}$ ventricular activation caused by ventricular ectopic beats, FV: fusion beat. See text for explanations. 
intermediate axis and an $\mathrm{HV}$ interval of $45 \mathrm{~ms}$, could also be observed (Fig. IB).

Carotid sinus massage produced a slowing of the junctional rhythm. There were longer pauses between the supraventricular conducted beats, followed at a cycle length of $550 \mathrm{~ms}$ by the second type of ventricular complexes (Fig. 2).

Lignocaine abolished the ventricular ectopic beats and slowed the junctional rhythm (Fig. 3). The cycle length was prolonged from 480 to $960 \mathrm{~ms}$, but before the development of the $960 \mathrm{~ms}$ cycle there was a junctional beat at $910 \mathrm{~ms}$ which excludes any obvious form of exit block.

\section{Discussion}

The interest of our observations resides in the demonstration of two ectopic foci responsible for

(A)
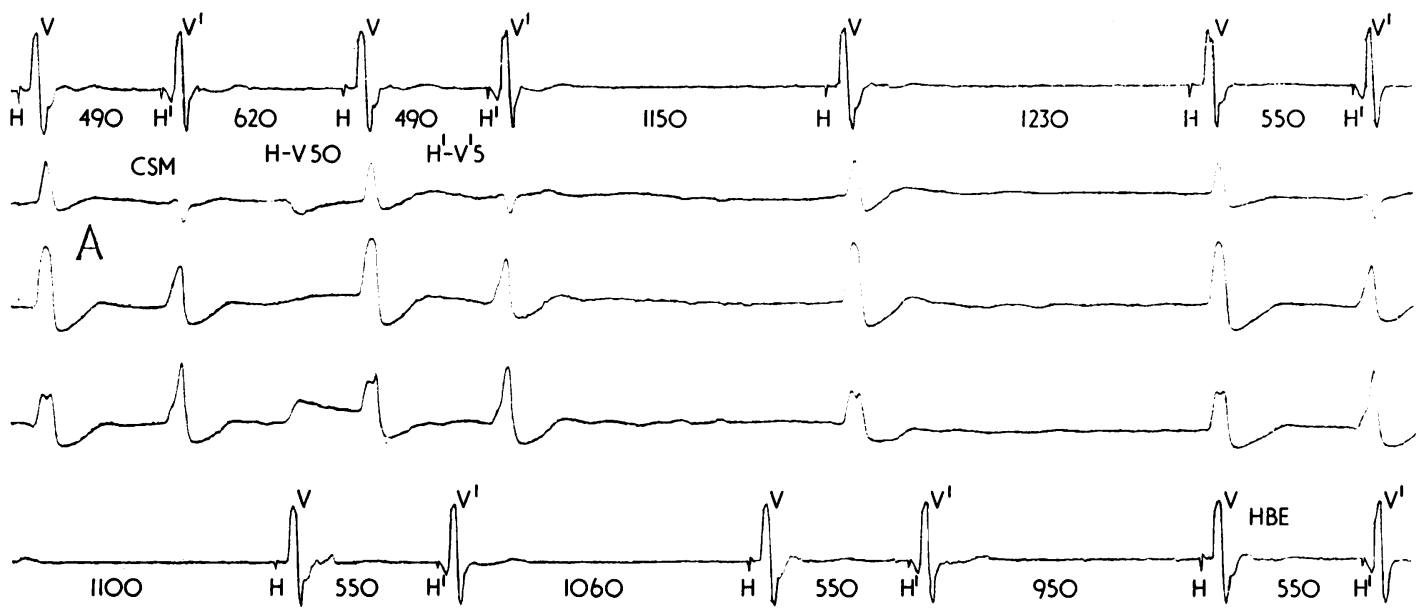

DI

(B)
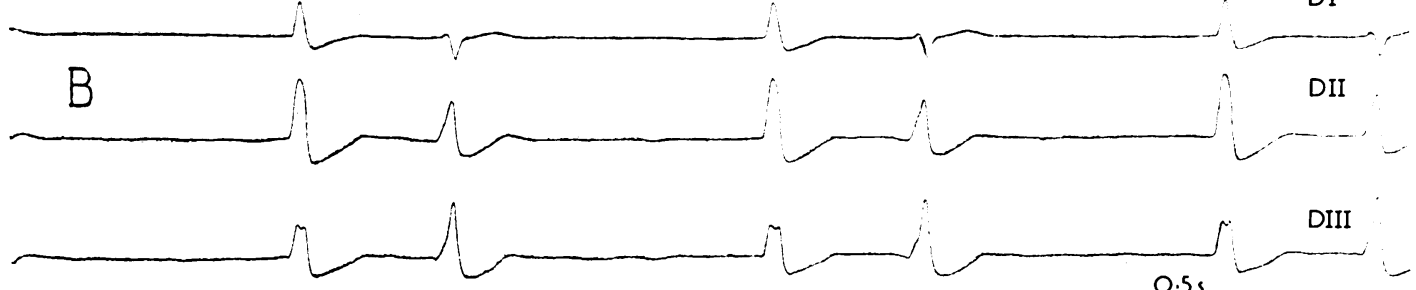

DIII

FIG. 2 The effect of carotid sinus massage (CSM) on the His bundle electrogram. $A$ and $B$ are continuous recordings.

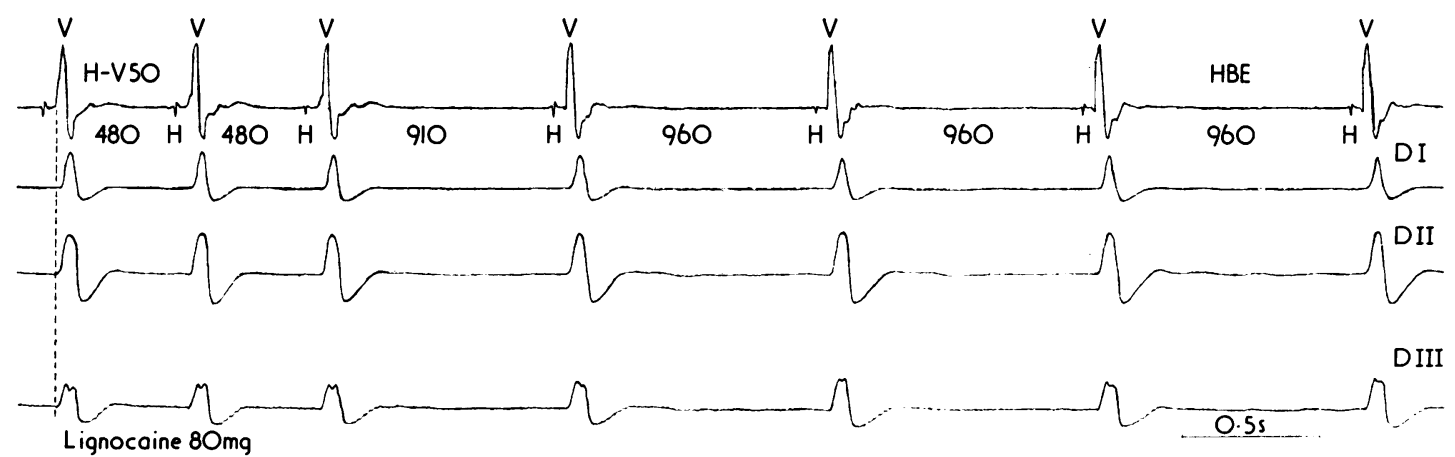

FIG. 3 The effect of lignocaine on junctional tachycardia. 
the alternating rhythm. The patient had a severe cardiopathy associated with chronic glomerulonephritis which favoured digitalis intoxication. Though the levels of the digitalis glycosides could not be estimated in the blood, the sequence of electrocardiographic abnormalities and the clinical circumstances strongly suggested digitalis toxicity.

Bidirectional and alternating tachycardia have been considered to result from enhanced impulse formation within the ventricles. The presence of two separate ventricular foci was assumed (Schwensen, 1922; Scherf and Bornemann, 1967). Recently it has been thought that the abnormal rhythm was the result of a single ectopic ventricular pacemaker located in the divisions of the left bundle-branch, the right and left shifts resulting from blocked transmission alternately in the posterior and anterior divisions of the bundle-branch (Cohen et al., 1973). Other explanations include a supraventricular focus located in the junctional area activating the ventricles with intermittent functional block of the bundle-branches (Luten, 1925), or its divisions (Rosenbaum et al., 1969), or the occurrence of junctional tachycardia in the presence of ventricular bigeminy, i.e. the presence of two ectopic foci, one supraventricular and the other one within the ventricles (Zimdahl and Townsend, 1954).

In our case the last explanation is the most likely. The presence of two types of ventricular activation, one preceded by an $\mathrm{H}$ potential at $50 \mathrm{~ms}$, the second one by an $\mathrm{H}^{\prime}$ deflection which coincided with the beginning of the QRS complex, are direct evidence in favour of the origin of the recorded beats. The presence of fusion beats between junctional and fascicular rhythm is also an argument in favour of the existence of two separate rhythms.

In Fig. IA, the seventh, eighth, and ninth beats all form part of the junctional rhythm and have a cycle length exactly half that of the junctional rhythm when each beat is followed by an ectopic. The eighth complex is a fusion beat. This suggests that the junctional rhythm is actually occurring at twice its apparent rate, when alternating fascicular ectopic beats depolarize the junctional focus. In other words the fascicular beats were followed by a fully compensatory pause of the junctional tachycardia.

Carotid sinus massage (Fig. 2) slowed the junctional rhythm and unmasked the presence of ventricular bigeminy responsible for the alternate rhythm. This suggests that in the bidirectional type of junctional tachycardia caused by digitalis toxicity the tachycardia is caused by the focus under vagal control (Bellet, 197I).

Bidirectional tachycardia appears to be a complex arrhythmia caused by several different mechanisms (Castellanos, I96I; Scherf and Cohen, I964; Dolara et al., 1970) which can show similar electrocardiographic configuration. His bundle electrography may help in the differentiation of the underlying mechanisms during this arrhythmia.

\section{References}

Bellet, S. (1971). Clinical Disorders of the Heart Beat, 3rd ed., p. I I 57. Lea and Febiger, Philadelphia.

Castellanos, A. (1961). The genesis of bidirectional tachycardias. American Heart fournal, 6r, 733.

Cohen, S. I., Deisseroth, A., and Hecht, H. S. (1973). InfraHis bundle origin of bidirectional tachycardia. Circulation, 47, 1260.

Dolara, A., Manetti, A., Pozzi, L., and Tordini, G. (1970). Bidirectional tachycardia. Cardiology, 53, 302.

Kastor, J. A. (1973). Digitalis intoxication in patients with atrial fibrillation. Circulation, 47, 888.

Kastor, J. A., and Goldreyer, B. N. (1973). Ventricular origin of bidirectional tachycardia: case report of a patient not toxic from digitalis. Circulation, 48, 897.

Luten, D. (1925). Clinical studies of digitalis: advanced toxic rhythms. Archives of Internal Medicine, 35, 87.

Morris, S. N., and Zipes, D. P. (1973). His bundle electrocardiography during bidirectional tachycardia. Circulation, 48, 32.

Pop, T., Cotoi, S., Luca, C., and Gavrilescu, S. (1972). The recording of A-V conduction system potentials. A simple bedside technique. Cor et Vasa, 14, 6r.

Puech, P., Grolleau, R., Baissus, C., Cabasson, J., and Latour, H. (1974). Tachycardie bidirectionnelle d'origine infrahisienne. Archives des Maladies du Coeur et des Vaisseaux, 67, 39.

Rosenbaum, M. B., Elizari, M. V., and Lazzari, J. O. (1969). The mechanism of bidirectional tachycardia. American Heart fournal, 78, 4.

Scherf, D., and Bornemann, C. (1967). Tachycardias with alternation of the ventricular complexes. American Heart fournal, 74, 667 .

Scherf, D., and Cohen, J. (1964). The Atrioventricular Node and Selected Cardiac Arrhythmias. Grune and Stratton, New York and London.

Schwensen, C. (1922). Ventricular tachycardia as the result of the administration of digitalis. Heart, 9, 199.

Zimdahl, W. T., and Townsend, C. E. (I954). Bidirectional ventricular tachycardia due to digitalis poisoning. American Heart fournal, 47, 304.

Requests for reprints to Professor S. Gavrilescu, str. Feuerbach 10, Timisoara, Rumania. 